\title{
Conditions for acid catalysed luminal nitrosation are maximal at the gastric cardia
}

\author{
H Suzuki, K lijima, A Moriya, K McElroy, G Scobie, V Fyfe, K E L McColl
}

Gut 2003;52:1095-1101

See end of article for authors' affiliations

\section{Correspondence to:}

Professor K E L McColl

Section of Medicine,

Gardiner Institute, Western

Infirmary, Glasgow

G11 6NT, UK:

K.E.L.McColl@

clinmed.gla.ac.uk

Accepted for publication 18 March 2003 Background: Saliva has a high nitrite concentration, derived from the enterosalivary recirculation of
dietary nitrate, and is the main source of nitrite entering the acidic stomach. Acidification of nitrite in
the presence of secondary amines or amides generates potentially carcinogenic $N$-nitroso compounds. The reaction is inhibited by ascorbic acid and catalysed by thiocyanate.

Aim: To determine whether there is intragastric regional variation in the chemical conditions promoting luminal nitrosation following nitrate ingestion.

Methods: Using microdialysis probes, we measured concentrations of nitrite, ascorbic acid, total vitamin C, and thiocyanate simultaneously in saliva, the distal oesophagus, cardia, and the proximal and distal stomach of 17 healthy volunteers before and following intragastric nitrate $(2 \mathrm{mmol})$ administration.

Results: The median $\mathrm{pH}$ in the distal oesophagus, cardia, and proximal and distal stomach were 7 , $2.6,1.9$, and 1.7, respectively, before, and were similar following nitrate administration. Mean nitrite concentration in the distal oesophagus was similar to that of saliva, being $29.1 \mu \mathrm{M}$ and $36.7 \mu \mathrm{M}$, respectively, before nitrate and increasing to $181.6 \mu \mathrm{M}$ and $203.3 \mu \mathrm{M}$ after nitrate ingestion. Within the stomach, mean (SEM) nitrite concentration following nitrate was higher in the cardia (45.5 (12.7) $\mu M)$ than in the mid $(7.8(3.1))(p<0.01)$ or distal $(0.8(0.6))(p<0.1)$ stomach, and ascorbic acid concentration was lower at the cardia (13.0 (6.1)) than in the mid (51 (19.2)) $(p<0.02)$ or distal (86 (29)) $(p<0.01)$ stomach. Consequently, the median ascorbic acid to nitrite ratio was lowest at the cardia (0.3) $(p<0.01)$ versus the mid (7.8) or distal $(40)$ stomach. Thiocyanate concentration was similar throughout the stomach.

Conclusions: The conditions favouring luminal generation of $\mathrm{N}$-nitroso compounds from dietary nitrate are maximal at the most proximal cardia region of the acidic stomach and may contribute to the high incidence of mutagenesis at this site. glands and secreted into the mouth. ${ }^{14}$ Bacteria on the dorsum of the tongue then reduce about $25 \%$ of the nitrate to nitrite. ${ }^{15}{ }^{16}$ The salivary glands also actively take up and secrete thiocyanate and its concentration in saliva is approximately $1 \mathrm{mmol} / \mathrm{l}$ and even higher in smokers. ${ }^{17}$ The latter anion may

also be secreted directly into gastric juice. ${ }^{17}$ Thiocyanate is a powerful catalyst of nitrosation of secondary amines by acidified nitrite. ${ }^{18}$ This delivery of nitrite and thiocyanate into the acidic environment of the stomach has therefore been regarded as a potentially important source of endogenous formation of carcinogenic $N$-nitroso compounds. ${ }^{12}$

Ascorbic acid is actively secreted into gastric juice ${ }^{19} 20$ and plays a key role in preventing acid catalysed luminal nitrosation. ${ }^{21}{ }^{22}$ It does this by effectively competing with the secondary amines and amides for nitrosating species formed by acidification of nitrite. ${ }^{21}{ }^{22}$ In this reaction acidified nitrite is reduced to nitric oxide and ascorbic acid oxidised to dehydroascorbic acid. ${ }^{23}{ }^{24}$ Stoichemically, one molecule of ascorbic acid can reduce two molecules of acidified nitrite to nitric oxide. ${ }^{23}{ }^{24}$ However, in the presence of dissolved oxygen, nitric oxide can be oxidised back to nitrite/nitrous acid. ${ }^{23-25}$ This recycling means that more than half the molar equivalent of ascorbic acid to nitrite is required to prevent formation of $\mathrm{N}$-nitroso compounds..$^{23-25}$ The ratio of ascorbic acid to nitrite is recognised to be a major determinant of generation of $N$-nitroso compounds within the acidic lumen of the stomach. ${ }^{24}$

We recently reported that the luminal concentrations of nitric oxide generated from the reaction between salivary nitrite and ascorbic acid in acidic gastric juice were maximal at the most proximal cardia region of the stomach. ${ }^{26}$ Nitric oxide is mutagenic at high concentrations, and we postulated that its diffusion into the adjacent epithelium could contribute to the high incidence of metaplasia and neoplasia at this localised anatomical site.

Our above observation regarding nitric oxide has stimulated us to compare the different anatomical regions of the upper 
A
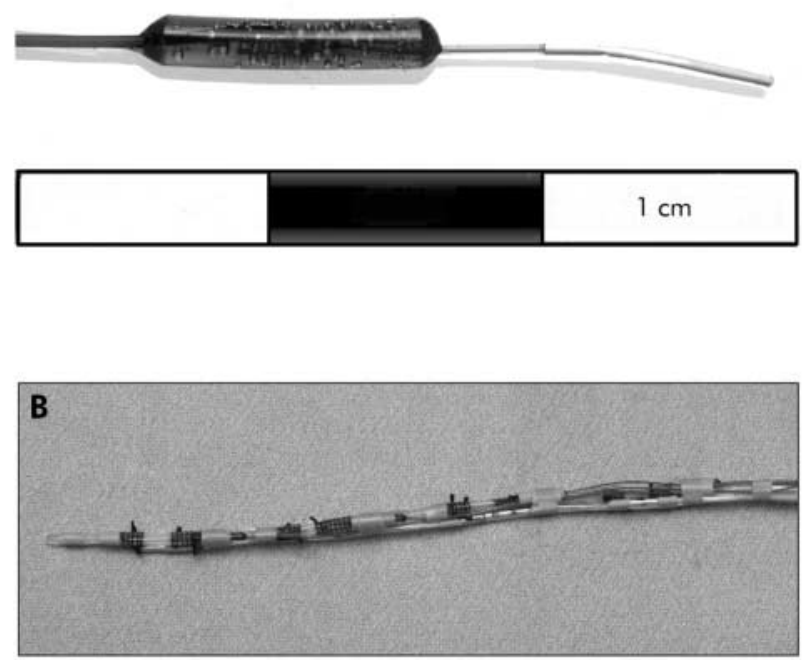

Figure 1 (A) Photograph of the microdialysis probe. The semipermeable membrane is on the most distal $1 \mathrm{~cm}$ segment of the probe. (B) Photograph of assembled apparatus. It consists of four microdialysis probes mounted on the outside of a nasogastric tube. The inlet and outlet tubes from each probe are contained within the lumen of the nasogastric tube. A Teflon feeding tube and multichannel $\mathrm{pH}$ sensor probe are also attached to the outside of the nasogastric tube.

gastrointestinal tract with respect to their concentrations of chemicals relevant to luminal nitrosation. Our findings indicate that the potential for acid catalysed luminal nitrosation arising from dietary nitrate is greatest in the most proximal cardia region of the stomach.

\section{AIM}

The aims of this study were to: (i) measure the concentrations of the chemicals relevant to acid catalysed luminal nitrosation (that is, nitrite, ascorbic acid, total vitamin $\mathrm{C}$, and thiocyanate) at different anatomical locations within the lumen of the human upper gastrointestinal tract; and (2) determine the effects of nitrate intake on their concentrations.

\section{MATERIALS AND METHODS}

The study involved 17 healthy asymptomatic volunteers. Each was confirmed to be $H$ pylori negative by the ${ }^{14} \mathrm{C}$ urea breath test. $^{27}$

\section{Microdialysis probe}

We used CMA flexible microdialysis probes (MAB 7.8.10; Biotech Instruments Ltd, Herts, UK) (fig IA) to allow measurement of the chemicals relevant to acid nitrosation within localised regions of the upper gastrointestinal tract. The probes have a fine $1 \mathrm{~m}$ long inlet tube leading to the microdialysis chamber and a similar outlet tube returning from this chamber. The inlet tube is attached to a microdialysis pump (Univentor 864 microdialysis syringe pump; Biotech Instruments Ltd) capable of driving six syringes simultaneously and perfused at $150 \mu \mathrm{l} / \mathrm{h}$ with distilled water degassed with helium. Due to the equilibration across the semipermeable membrane, the concentration of solutes in the sample obtained from the outlet tube (termed microdialysis sample) provides a measure of their concentration in the test solution. ${ }^{28}$ It takes 10 minutes for the perfusate to return from the microdialysis chamber to the end of the outlet tube and therefore one includes this lag time before starting and completing the microdialysis sample collection.

We undertook extensive validation studies to confirm the reliability of the microdialysis probes to determine the concentration of nitrite, ascorbic acid, total vitamin C, and thiocyanate in both aqueous solutions and human gastric juice at $37^{\circ} \mathrm{C} \cdot .^{29}$ In these studies, the concentration of the chemical in the microdialysis sample is compared with that in the solution in which the probe is placed and the former expressed as a percentage of the latter representing the recovery value. Eight studies were performed in both aqueous solution and gastric juice for each chemical and at each of the following $\mathrm{pH}$ values: $1.5,2.5,3.5,5.5$, and 7.0. Recovery of greater than $60 \%$ was obtained under every condition studied and the standard errors for each set of eight experiments ranged from $\pm 1.1 \%$ to $\pm 6.8 \%$. We also performed studies in which we added $1 \mathrm{ml}$ boluses of nitrite into hydrochloric acid at varying $\mathrm{pH}$ and containing various concentrations of ascorbic acid in order to simulate the conditions occurring near the gastrooesophageal junction. Under these dynamic conditions where nitrite was in excess of ascorbic acid, the microdialysis probe showed the same recovery as for the static studies. Under dynamic studies in which ascorbic acid was in excess of nitrite, the microdialysis sample showed no nitrite whereas some nitrite was detected in the sample taken directly from the test solution. By measuring nitric oxide in the test solution, we were able to show that all of the nitrite added to the stomach in the presence of excess ascorbic acid had been converted to nitric oxide. The nitrite detected in the sample taken directly from the stomach was artefactual due to nitric oxide reverting to nitrite within the $\mathrm{NaOH}$ solution into which the sample is collected. This artefact did not occur with the microdialysis probe as nitric oxide diffuses out of the collecting tubes during its 10 minute passage along it and prior to collection in the $\mathrm{NaOH}$ solution.

\section{Assembly of microdialysis probes for in vivo studies}

Four microdialysis probes were secured in individual recesses created $5 \mathrm{~cm}$ apart in a $3.3 \mathrm{~mm}$ diameter nasogastric tube (Rusch Manufacturing, Lurgan, UK). Their inlet and outlet tubes were contained within the lumen of the tube. A multiple channel pH catheter (Synectics Medical Ltd, Enfield, UK) was attached to the outside of the nasogastric tube with $\mathrm{pH}$ sensors positioned alongside each microdialysis probe and an additional sensor located $\mathrm{l} \mathrm{cm}$ proximal to the cardia microdialysis probe (fig 1B). Outputs from the $\mathrm{pH}$ sensors were digitalised (DAS 1201 data acquisition board; Keithley Instruments Ltd, Reading, Berkshire, UK), monitored on a computer screen during the procedure, and stored on computer for subsequent analysis.

Prior to each study, recovery of each probe fully assembled on the nasogastric tube was assessed for each individual chemical at $37^{\circ} \mathrm{C}$ at $\mathrm{pH} 1.5,2.5$, and 7 . Following each study, individual probes were then removed from the nasogastric tube, cleaned, and sterilised with Cidex (Johnson and Johnson, Newark, New Jersey, USA) before being remounted into a fresh nasogastric tube.

\section{Clinical procedure}

Subjects presented in the morning having fasted since the previous evening. In addition, they were instructed to avoid nitrate rich foods for 24 hours prior to the procedure. The probe assembly was passed perorally and positioned so that the $\mathrm{pH}$ sensor sited $1 \mathrm{~cm}$ proximal to the cardia microdialysis probe recorded oesophageal $\mathrm{pH}(>4)$ and the $\mathrm{pH}$ sensor at the cardia microdialysis probe recorded gastric $\mathrm{pH}(<2.5)$. This ensured that the cardia microdialysis probe was located just distal to the gastro-oesophageal junction as the $\mathrm{pH}$ step up corresponds to the squamocolumnar junction under fasting conditions. ${ }^{30}$ The position of the assembly was checked by an abdominal $x$ ray. Subjects lay semirecumbent throughout the study. The $\mathrm{pH}$ being recorded by each sensor was closely monitored during each study and the position of the tube adjusted if required to maintain its correct location relative to the gastro- oesophageal junction.

After confirmation of satisfactory positioning, the first 15 minute collections of the microdialysis samples were discarded and the following 40 minutes collected for analyses. 
Following this basal collection, $2 \mathrm{mmol}$ potassium nitrate in $25 \mathrm{ml}$ water was administered intragastrically via a fine Teflon feeding tube attached to the nasogastric tube. This dose of nitrate is equivalent to that in a standard portion of lettuce. ${ }^{3 .}$ Forty minutes after administering potassium nitrate, further microdialysis collections were obtained for 40 minutes. The delay between administration of nitrate and commencing collections is to allow time for nitrate to be absorbed, secreted in saliva, and converted in the mouth to nitrite.

The microdialysis samples for ascorbic acid and total vitamin C were collected into a glass vial (No 1) containing 25 $\mu \mathrm{l}$ of a solution of $2 \%$ metaphosphoric acid and $0.5 \%$ sulphamic acid and were further diluted with equal volumes of metaphosphoric/sulphamic acid solution for ascorbic acid and with $12 \mathrm{mg} / \mathrm{ml}$ dithiothreitol in metaphosphoric/ sulphamic acid solution for total vitamin C samples. Nitrite and thiocyanate samples were collected into a glass vial (No 2) containing $20 \mu \mathrm{l}$ of $1 \mathrm{M} \mathrm{NaOH}$. The two different collections from each collecting tube were achieved by alternating the microdialysis collecting tube between vials Nos 1 and 2 every two minutes. Over each 40 minute collecting period, $50 \mu \mathrm{l}$ were obtained from each microdialysis probe for ascorbic acid/total vitamin $\mathrm{C}$ and $50 \mu \mathrm{l}$ for nitrite/thiocyanate. The vitamin $\mathrm{C}$ samples were frozen at $-70^{\circ} \mathrm{C}$ for analysis within four weeks and nitrite and thiocyanate samples were stored at $4^{\circ} \mathrm{C}$ for analysis on the same day.

Venous blood was obtained from an indwelling intravenous catheter every 15 minutes for determination of serum nitrate and plasma ascorbic acid and total vitamin C. Samples were centrifuged at $3000 \mathrm{rpm}$ at $4^{\circ} \mathrm{C}$ for 10 minutes and the supernatant for plasma ascorbic acid and total vitamin $\mathrm{C}$ were diluted with equal volumes of $2 \%$ metaphosphoric acid- $0.5 \%$ sulphamic acid with or without $12 \mathrm{mg} / \mathrm{ml}$ of dithiothreitol, snap frozen in liquid nitrogen, and stored at $-70^{\circ} \mathrm{C}$ until analysis within four weeks. The supernatant for serum nitrate was transferred into a plain test tube and frozen at $-20^{\circ} \mathrm{C}$ until analysis within four weeks.

Samples of saliva were obtained every 15 minutes for nitrite and thiocyanate determination. This was done by asking the patient to spit into a sterile container and $500 \mu \mathrm{l}$ were immediately added to $50 \mu \mathrm{l}$ of $1 \mathrm{M} \mathrm{NaOH}$ in a $1.5 \mathrm{ml}$ plastic tube and stored at $4^{\circ} \mathrm{C}$ until analysis on the same day. Prior to analysis, saliva samples were centrifuged at $13000 \mathrm{rpm}$ for two minutes using a microcentrifuge and the supernatant was analysed.

\section{Chemical analyses}

Determination of ascorbic acid and total vitamin C concentrations

Samples were analysed using high performance liquid chromatography and an electrochemical detector, as described by Sanderson and colleagues. ${ }^{32}$ The assay measures ascorbic acid. Addition of dithiothreitol reduces any ascorbic acid which has been oxidised to dehydroascorbic acid back to ascorbic acid and this measurement is referred to as total vitamin C.

Determinations of nitrite and thiocyanate concentrations Samples were analysed against known concentrations of nitrite or thiocyanate in a 96 well microplate using the modified Greiss reagent for nitrite analysis ${ }^{25}$ and the Bowler method for thiocyanate. ${ }^{33}$ Colorimetric analysis was performed 20 minutes after addition of the Greiss reagent using a $540 \mathrm{~nm}$ filter for nitrite and immediately after addition of ferric nitrate in nitrous acid using a $450 \mathrm{~nm}$ filter for thiocyanate.

\section{Determination of serum nitrate concentrations}

After thawing, serum samples were filtered through a $10 \mathrm{kDa}$ microfilter (Microcon 10; Millipore UK Ltd, Watford, UK) to remove high molecular weight substances. Nitrate was reduced to nitrite using bacterial nitrate reductase, as previously described. ${ }^{34}$ Nitrite was then measured by the Greiss reagent as described above.

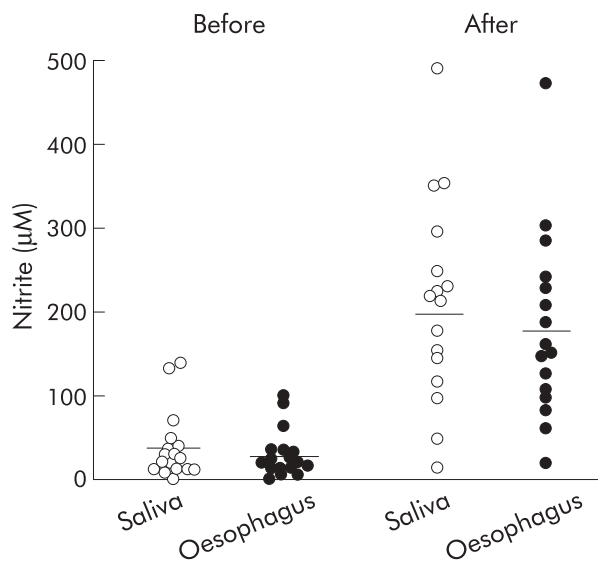

Figure 2 Individual salivary and oesophageal nitrite concentrations before and after nitrate administration. The after nitrate sample was collected over the 40 minute period starting 40 minutes after nitrate administration. The horizontal lines represent mean values. Both salivary and oesophageal nitrite were increased following nitrate administration $(p<0.01)$. Salivary and oesophageal nitrite concentrations were not significantly different from each other either before or after nitrate dosing.

\section{Statistical analyses}

All data are presented as mean (SEM) unless otherwise stated. The $\mathrm{pH}$ data and ascorbic acid/nitrite ratios for the different regions of the upper gastrointestinal tract are presented as medians as they are exponential functions. Paired data were analysed using a one sample Wilcoxon test. In order to calculate the ascorbic acid to nitrite ratio, any samples with undetectable levels of ascorbic acid or nitrite concentrations were allocated a concentration of $1 \mu \mathrm{M}$, the approximate lower limit of detection for both ascorbic acid and nitrite using our analytic methods. If both ascorbic acid and nitrite were undetectable, these samples were excluded from analysis. Statistical testing was performed using the one sample Wilcoxon test. Bonferroni correction was applied for multiple comparisons. A two tailed $\mathrm{p}$ value $<0.05$ was considered to be statistically significant.

\section{Ethics}

The study was approved by the North Glasgow University NHS Trust Ethics Committee and each subject gave written informed consent.

\section{RESULTS}

Twenty one volunteers were recruited. Four were unable to tolerate the procedure for the duration of the experiment and were excluded, leaving 17 available for analysis. Mean age was 32.1 years (range 18-52) and 12 were males.

\section{Blood}

Prior to nitrate administration, fasting serum nitrate concentration was 18.5 (1.5) $\mu \mathrm{M}$. Following ingestion of $2 \mathrm{mmol}$ nitrate, serum nitrate increased threefold within 30 minutes, peaking 25 minutes after nitrate administration at 59.5 (2.4) $\mu \mathrm{M}$, and remained at this level for at least the following 60 minutes. Plasma ascorbic acid concentration was 52.2 (4.9) $\mu \mathrm{M}$ and that of total vitamin $\mathrm{C}$ was 54.6 (4.9) $\mu \mathrm{M}$. Plasma concentrations of ascorbic acid and total vitamin $\mathrm{C}$ were unchanged following nitrate administration.

\section{Saliva}

Prior to insertion of the probe assembly, the saliva nitrite concentration was $112.5(30.0) \mu \mathrm{M}$ and fell to 36.7 (9.9) $\mu \mathrm{M}$ at 15 minutes after insertion of the microdialysis assembly $(p<0.01)$. Following administration of nitrate, the saliva nitrite concentration increased sixfold over the following 30 minutes and remained elevated for at least the following 60 minutes. Prior to passing the probe assembly, the saliva thiocyanate 
Before nitrate
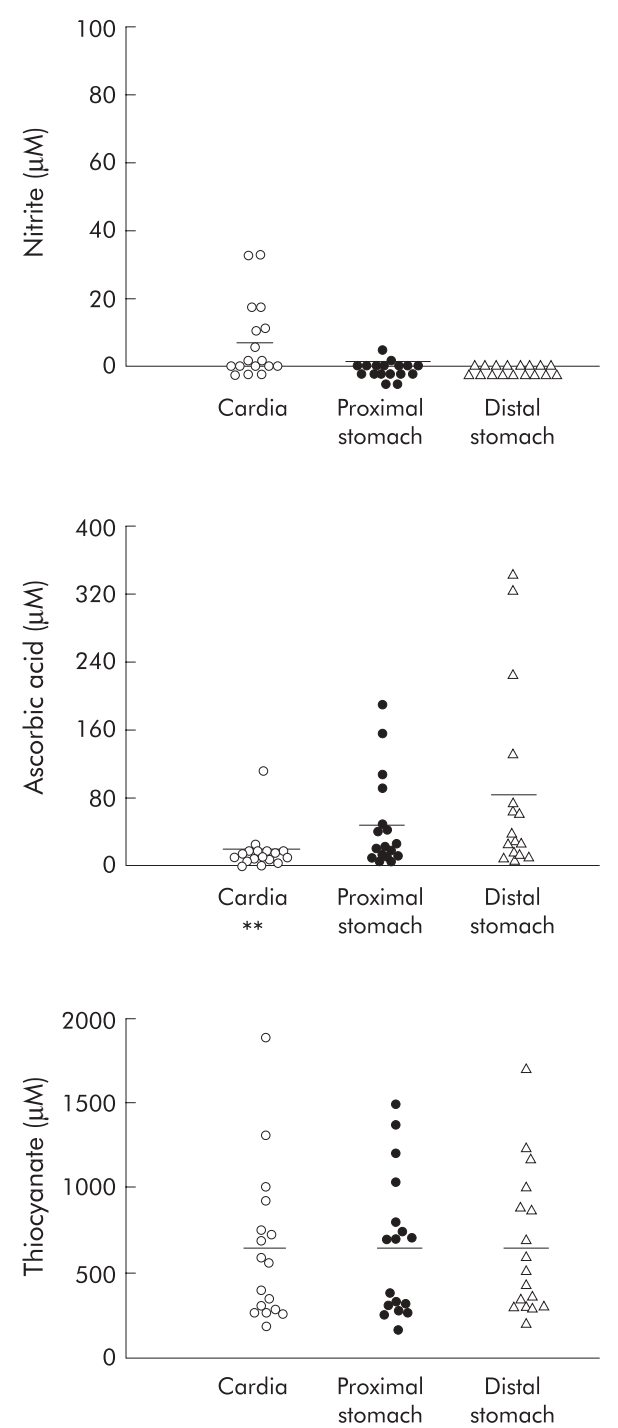
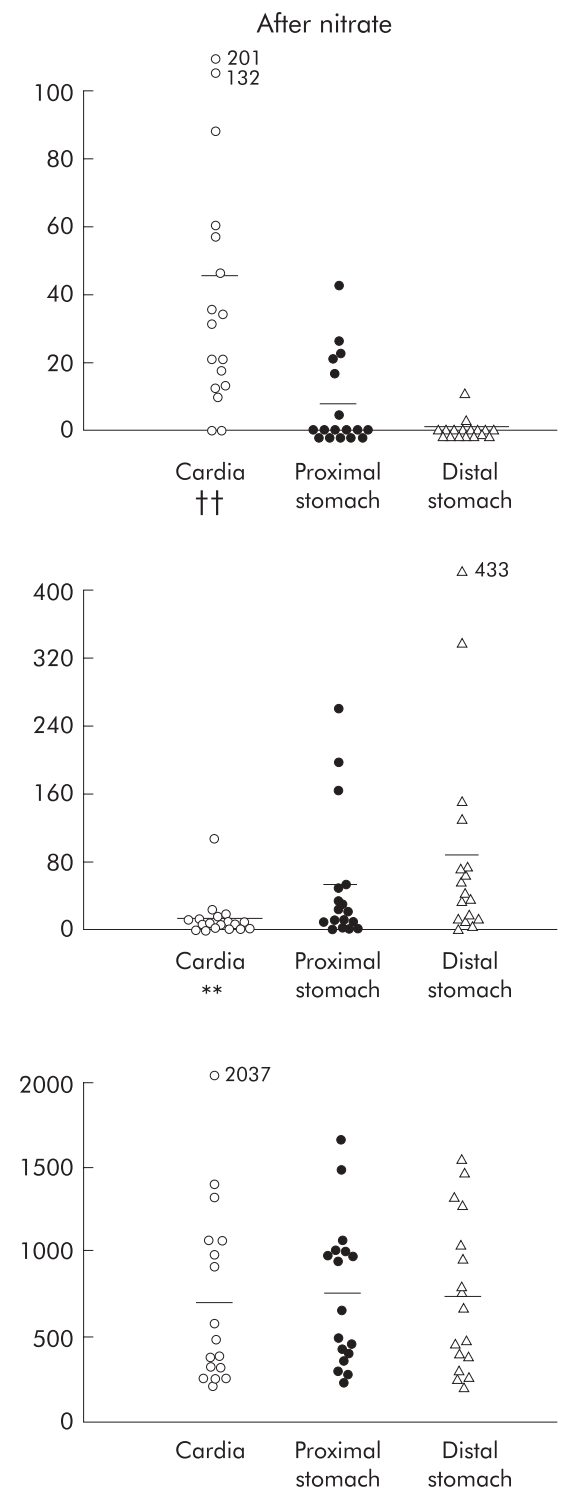

Figure 3 Concentrations of nitrite, ascorbic acid, and thiocyanate in the stomach before and after a nitrate meal. The after nitrate sample was collected over the 40 minute period starting 40 minutes after nitrate administration. The horizontal lines represent mean concentrations. Outliers are indicated with values next to the symbols. Statistically significant differences are indicated: for nitrite, $+\uparrow p<0.01$ compared with the cardia before nitrate administration and compared with the proximal and distal stomach after nitrate; for ascorbic acid, $* * p<0.01$ compared with the proximal and distal stomach both before and following nitrate.

concentration was 2597 (481) $\mu \mathrm{M}$ and following placement of the assembly this fell to $1360(283) \mu \mathrm{M}(\mathrm{p}<0.01)$ and remained at this level throughout the remainder of the study.

\section{Oesophagus}

The median $\mathrm{pH}$ of the distal oesophagus was 7, and was unaffected by administration of nitrate. Fasting nitrite concentration in the distal oesophagus was 29.1 (7.1) $\mu \mathrm{M}$ which was similar to the fasting saliva nitrite concentration of 36.7 (9.9) $\mu \mathrm{M}$ (fig 2). Following nitrate administration, nitrite concentration in the distal oesophagus increased to $181.6(26.4) \mu \mathrm{M}$ at 55 minutes which again was similar to that of saliva nitrite which increased to 203.3 (30.3) $\mu \mathrm{M}(\mathrm{p}<0.01 v$ fasting levels $)$ (fig 2).

Both ascorbic acid and total vitamin C concentrations were low in the oesophagus. Ascorbic acid concentration was 11.5 (2.6) $\mu \mathrm{M}$ before nitrate administration and was slightly lower at $9.8(2.7) \mu \mathrm{M}$ after nitrate. Total vitamin $\mathrm{C}$ concentration was 11.8 (1.9) $\mu \mathrm{M}$ before nitrate and 10.1 (1.7) $\mu \mathrm{M}$ after nitrate.

Thiocyanate concentration in the distal oesophagus before nitrate administration was 809 (145) $\mu \mathrm{M}$ which was lower than the corresponding value in saliva at 1360 (283) $\mu \mathrm{M}$ $(\mathrm{p}<0.01)$. Following nitrate administration, thiocyanate concentration in the distal oesophagus was unchanged at 917 (160) $\mu \mathrm{M}$ and again lower than that in saliva at 1286 (235) $\mu \mathrm{M}$ $(\mathrm{p}<0.01)$.

\section{Stomach}

$\mathrm{pH}$

Prior to nitrate administration, the median $\mathrm{pH}$ of the cardia, proximal stomach, and distal stomach were 2.6, 1.9, and 1.7, respectively. Following nitrate, the $\mathrm{pH}$ of the different regions of the stomach were 2.8, 1.7, and 1.5, respectively. The percentage of time $\mathrm{pH}$ was above 4 in the cardia, proximal stomach, and distal stomach were $18.5 \%, 0 \%$, and $0 \%$. Following nitrate, the percentage of time $\mathrm{pH}$ was above 4 were $23 \%$, $0 \%$, and $0 \%$ at the respective sites.

\section{Nitrite}

Prior to nitrate administration, nitrite concentration within the stomach was low, being $7.6(2.7) \mu \mathrm{M}$ at the cardia, 0.4 (0.3) in the proximal stomach, and $0(0.1) \mu \mathrm{M}$ in the distal 


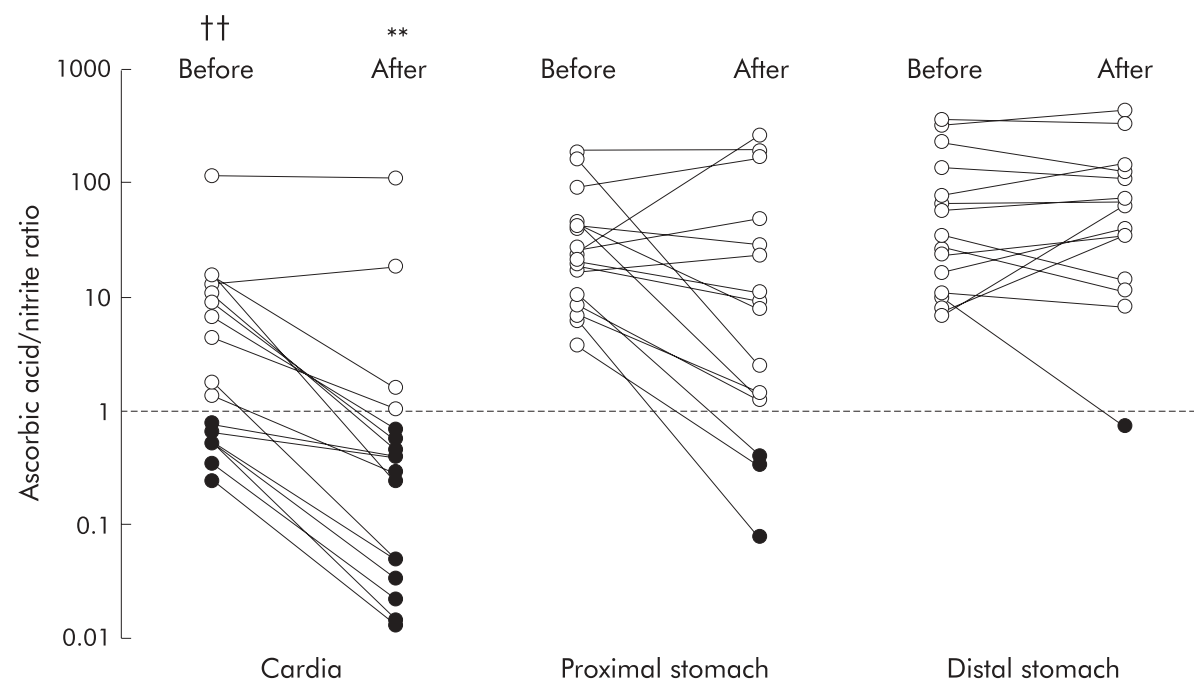

Figure 4 Ratio of ascorbic acid to nitrite in the different regions of the stomach before and after nitrate, using a logarithmic scale. The after nitrate sample was collected over the 40 minute period starting 40 minutes after nitrate administration. $\uparrow \dagger p<0.01$ compared than the proximal and distal stomach before nitrate; ${ }^{*} p<0.02$ compared with the cardia before nitrate, and compared with the proximal and distal stomach after nitrate $(p<0.01)$.

stomach. Although there was a trend towards higher levels at the cardia, this was not statistically significant. Following nitrate administration, nitrite concentration increased significantly at the cardia to $45.5(12.7) \mu \mathrm{M}(\mathrm{p}<0.01)$ but showed no significant change in the proximal or distal stomach (fig 3 ). Following the nitrate meal, nitrite concentration at the cardia was higher than in the proximal or distal stomach $(\mathrm{p}<0.01)$.

The nitrite concentration in the cardia before nitrate $(7.6$ $(2.7) \mu \mathrm{M})$ was lower than that in the distal oesophagus (29.1 $(7.1) \mu \mathrm{M})(\mathrm{p}<0.01)$. Following the nitrate meal, the nitrite concentration at the cardia $(45.5(12.7) \mu \mathrm{M})$ was again lower than that of the distal oesophagus $(181.6(26.4) \mu \mathrm{M})(\mathrm{p}<0.01)$ (fig 3).

\section{Ascorbic acid and total vitamin C}

Prior to nitrate administration, ascorbic acid concentration was lower in the cardia at $14.9(6.2) \mu \mathrm{M}(\mathrm{p}<0.01)$ than in the proximal $(47.4(13.8) \mu \mathrm{M})$ or distal $(83.5(27.3) \mu \mathrm{M})$ stomach (fig 3). Following nitrate, concentrations of ascorbic acid at the cardia, and proximal and distal stomach were unchanged at 13.0 (6.1) $\mu \mathrm{M}, 51.5 \quad(19.2) \mu \mathrm{M}$, and 86.3 (29.3) $\mu \mathrm{M}$, respectively (fig 3 ).

Before nitrate administration, total vitamin $\mathrm{C}$ concentration was also lowest at the cardia at $18.6(7.0) \mu \mathrm{M}(\mathrm{p}<0.01)$ than in the proximal $(55.9(14.2) \mu \mathrm{M})$ or distal $(84.9(25.8) \mu \mathrm{M})$ stomach. Following nitrate, total vitamin $\mathrm{C}$ levels at all sites were non-significantly higher at 24.3 (8.4) $\mu \mathrm{M}, 87.2$ (31.0) $\mu \mathrm{M}$, and 112.9 (30.0) $\mu \mathrm{M}$ for the cardia, proximal stomach, and distal stomach, respectively.

Prior to nitrate administration, the median ratio of ascorbic acid to total vitamin $C$ was 0.65 in the cardia, 0.73 in the proximal stomach, and 0.76 in the distal stomach. Following nitrate, the mean ratio fell non-significantly to $0.46,0.54$, and 0.60 for the cardia, proximal stomach, and distal stomach, respectively.

\section{Thiocyanate}

Prior to nitrate administration, thiocyanate concentrations were similar in the cardia, proximal stomach, and distal stomach at 628 (111) $\mu \mathrm{M}, 645$ (102) $\mu \mathrm{M}$, and 648 (104) $\mu \mathrm{M}$, respectively (fig 3 ). They did not change following nitrate administration. Thiocyanate concentration in the stomach was about $80 \%$ of that in the oesophagus and about $50 \%$ of that in saliva.

\section{Ratio of ascorbic acid to nitrite}

Prior to nitrate administration, the ratio of ascorbic acid to nitrite (median, range) was much lower in the cardia (1.5, $0.2-112)(\mathrm{p}<0.01)$ than in the proximal $(20.8,3.7-193)$ or distal $(27.7,7-351)$ stomach (fig 4). Following nitrate, the ratio at the cardia fell to $0.3(0-108)(\mathrm{p}<0.02 v$ cardia before nitrate), but the ratio in the proximal $(7.8,0-264)$ and distal $(40,0.7-428)$ stomach remained unchanged (fig 4).

\section{DISCUSSION}

Previous studies have examined the concentrations of chemicals relevant to luminal nitrosation in saliva and aspirated mixed gastric juice. ${ }^{22}{ }^{35}$ We have extended previous work by measuring their luminal concentrations in different anatomical regions of the upper gastrointestinal tract. This shows that the most proximal cardia region of the stomach has the chemical conditions most favourable for luminal generation of $\mathrm{N}$-nitroso compounds.

Concentrations of both nitrite and thiocyanate were found to be high in the distal oesophagus and similar to those in saliva. Nitrite concentration in the oesophagus increased approximately sixfold following nitrate ingestion consistent with it originating from the enterosalivary recirculation of nitrate and its reduction by buccal bacteria. ${ }^{14-16}$ The high concentrations of nitrite and thiocyanate in the oesophagus may be largely due to swallowing as well as diffusion distributing these anions produced in the mouth throughout the oropharyngeal-oesophageal cavity. Nitrate and thiocyanate are secreted by many exocrine glands ${ }^{36}{ }^{37}$ and may therefore be secreted by the oesophageal submucosal glands. In addition, there may be reduction of nitrate to nitrite within the oesophageal lumen by bacterial nitrate reductase activity known to be present in aspirated saliva. ${ }^{38}$

Concentrations of both nitrite and thiocyanate measured in the saliva sample obtained prior to insertion of the orogastric tube were, respectively, three times and two times higher than those measured in saliva when the tube was in place. This can be explained by the presence of the tube stimulating buccal secretions. Stimulation of salivary secretion has been shown to reduce the concentration of nitrate and nitrite in saliva. ${ }^{15}$ However, the output of nitrate increases on stimulation and more nitrate may be reduced to nitrite during mechanical stimulation. ${ }^{39}$ 


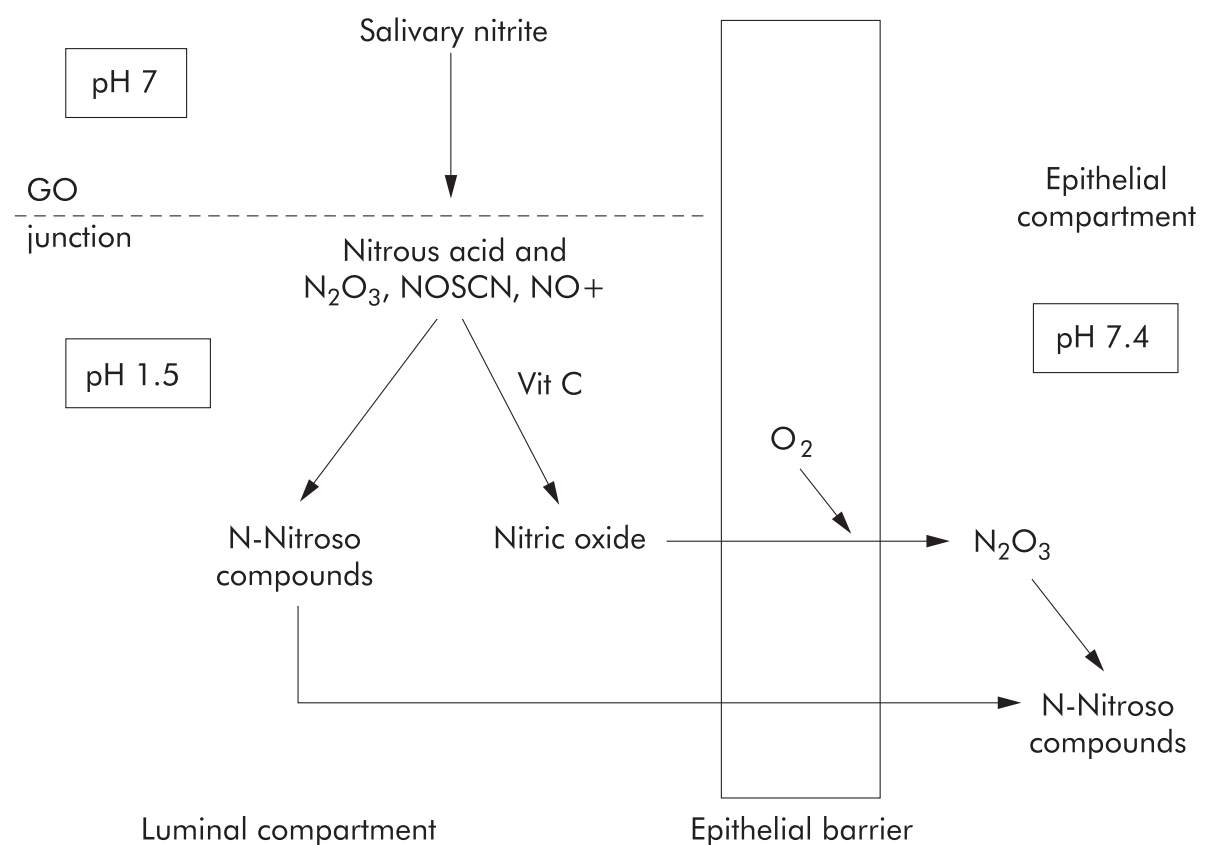

Figure 5 Chemical reactions occurring when nitrite enters acidic gastric juice. Nitrite is converted to nitrous acid and nitrosating species, including nitrosothiocyanate. In the absence of ascorbic acid, these can react with nitrososatable species to form $\mathrm{N}$-nitroso compounds which may diffuse into the adjacent epithelium. Ascorbic acid in gastric juice prevents this luminal nitrosation by converting the nitrosating species to nitric oxide. However, nitric oxide can diffuse into the adjacent epithelium and there react with oxygen to reform nitrosating species and $\mathrm{N}$-nitroso compounds. In the acid secretory stomach, both these pathways of $\mathrm{N}$ - nitroso compound generation operate maximally at the gastric cardia. GO, gastro- oesophageal.

Our studies have also demonstrated that there are marked differences in the concentrations of nitrite and ascorbic acid in different anatomical regions of the stomach. Under fasting conditions, little nitrite was detected in the stomach. However, following nitrate ingestion, the nitrite concentration increased in the most proximal cardia region of the stomach but showed no significant rise in the mid or distal stomach. Consequently, the nitrite concentration after nitrate ingestion was highest in the gastric cardia.

The observation that the nitrite concentration was highest in the cardia region of the stomach is consistent with the fact that nitrite enters the acid secreting stomach via the oesophagus which opens into the gastric cardia. When this nitrite passes into the more distal stomach, its concentration will fall due to dilution by gastric juice. In addition, acidic gastric juice containing ascorbic acid rapidly converts nitrite to nitrous acid and nitric oxide and the latter will rapidly diffuse into the surrounding epithelium. ${ }^{25} 40$

Concentrations of ascorbic acid and total vitamin $\mathrm{C}$ also showed marked intragastric regional variations both being lower in the cardia region than in the mid or distal stomach. This pattern was apparent both before and following nitrate ingestion.

The reason for the concentration of ascorbic acid and total vitamin $\mathrm{C}$ being lowest in the most proximal cardia region of the stomach is unclear. Vitamin $C$ present in fasting gastric juice is believed to be due to its active secretion by the gastric mucosa. ${ }^{19}{ }^{20}$ The cells responsible for secreting the vitamin into gastric juice are not known but biopsies from different regions of the stomach have shown that the mucosa levels of vitamin $\mathrm{C}$ are highest in the antrum. ${ }^{41}$

In contrast with nitrite and ascorbic acid, there was no gradient in the intragastric concentration of thiocyanate with substantial concentrations being present throughout the stomach. The concentration of thiocyanate in the stomach was $80 \%$ of that in the oesophagus and $50 \%$ of that in saliva.

The fact that the cardia region of the stomach had both the highest nitrite concentration and lowest ascorbic acid concen- tration meant that the ratio of ascorbic acid to nitrite was markedly lower in the cardia than in the more distal stomach. Before nitrate administration, the median ascorbic acid to nitrite ratio at the cardia was 1.5 versus 20.8 in the mid and 27.7 in the distal stomach. After nitrate, the ratio in the cardia was only 0.3 compared with 7.8 in the mid and 40 in the distal stomach. The ratio of ascorbic acid to nitrite is a critical determinant of acid nitrosation. ${ }^{23}{ }^{24}$ When ascorbic acid is in excess of nitrite, acid nitrosation is prevented. ${ }^{23}{ }^{24}$ These observations indicate that the potential for intragastric acid catalysed luminal nitrosation will not be uniform throughout the length of the stomach but will be maximal in the most proximal cardia region. At this location, intragastric nitrite is maximal, intragastric ascorbic acid minimal, and thiocyanate is available to catalyse the nitrosation process.

The clinical significance of our observations is that the anatomical location of maximal potential for acid catalysed luminal nitrosation corresponds with the location of the highest incidence of epithelial mutagenesis within the healthy acid secreting stomach. ${ }^{1-3}$ It is tempting to propose that luminally generated $N$-nitroso compounds may be contributing to the high incidence of metaplasia and neoplasia at the gastric cardia. $N$-nitroso compounds can rapidly diffuse into the adjacent epithelium ${ }^{42}$ and therein be metabolically activated to powerful DNA alkylating agents. ${ }^{43}{ }^{44}$ In addition, many $N$-nitroso compounds are unstable ${ }^{45}$ and therefore their epithelial effects will be maximal nearest their site of formation.

The findings of our current study are consistent with our previous observation that nitric oxide levels are maximal at the gastric cardia. ${ }^{26}$ In the present study, the concentration of nitrite was similar in buccal saliva and down as far as the distal oesophagus but then fell substantially on entering the gastric cardia. The fall in nitrite concentration between the distal oesophagus and cardia can be explained by the acidic gastric juice and its ascorbic acid content converting nitrite to nitric oxide.

Observations in our earlier study together with those of our present study indicate that two distinct luminal mechanisms 
both potentially leading to epithelial DNA damage are occurring maximally at the most proximal cardia region of the acid secreting stomach (fig 5). The first involves generation of high luminal concentrations of nitric oxide arising from the reaction between salivary nitrite and gastric juice ascorbic acid. This nitric oxide will diffuse into the adjacent epithelium and within the cells form nitrosating species which can directly and indirectly damage DNA. ${ }^{46}$ The second mechanism which is reported in the present study involves the generation of nitrosating species within the lumen due to the acidification of nitrite in the absence of adequate ascorbic acid. These nitrosating species formed in the lumen may react with nitrogenous compounds present in the lumen to form $N$-nitroso compounds which may then diffuse into the epithelial cells to damage DNA. The first mechanism is promoted by the presence of ascorbic acid whereas the second is promoted by the lack of ascorbic acid. Both mechanisms may operate maximally at this site although not simultaneously. When a bolus of nitrite laden saliva enters the cardia the ascorbic acid will convert much of it to nitric oxide. In the process, ascorbic acid will be consumed leading to the second mechanism now occurring at that same site. A common factor driving both processes is the delivery of nitrate derived nitrite into the acidic cardia region of the stomach.

Further studies are required to determine whether this nitrate derived nitrosative chemistry focused at the most proximal cardia region of the acid secreting stomach is contributing to the high incidence of mutagenesis at this anatomical site.

\section{ACKNOWLEDGEMENT}

This study was funded by a grant from the Biomedical and Clinical Research Committee of the Scottish Home and Health Department.

\section{Authors' affiliations}

H Suzuki, K lijima, A Moriya, K McElroy, G Scobie, V Fyfe, K E L McColl, Section of Medicine, Gardiner Institute, Western Infirmary, Glasgow, UK

\section{REFERENCES}

1 Hansen S, Melby K K, Aase S, et al. Helicobacter pylori infection and risk of cardia cancer and non-cardia gastric cancer. Scand J Gastroenterol 1999:4:353-60.

2 Spechler SJ. The role of gastric carditis in metaplasia and neoplasia at the gastresophageal junction. Gastroenterology 1999;117:218-28.

3 de Mas Chr-R, Kramer M, Seifert E, et al. Short Barrett: Prevalence and risk factors. Scand J Gastroenterol 1999;34:1065-70.

4 Hansen S, Wiig JN, Giercksky KE, et al. Esophageal and gastric carcinoma in Norway 1958-1992: incidence time trend variability according to morphological subtypes and organ subtypes. Int J Cancer 1997:71:340-4

5 Brown LM, Swanson CA, Gridley G, et al. Adenocarcinoma of the esophagus: role of obesity and diet. J Natl Cancer Inst 1995;87:104-9. 6 Powell J, McConkey CC. Increasing incidence of adenocarcinoma of the gastric cardia and adjacent sites. Br J Cancer 1990;62:440-3.

7 Fischermann K, Bech I, Andersen B. Diagnostic value of the augmented histamine test in cancer of the upper part of the stomach. ScandJ Gastroenterol 1969:4:517-19.

8 MacDonald WC. Clinical and pathologic features of adenocarcinoma of the gastric cardia. Cancer 1972;29:724-32.

9 Hansen S, Vollset S E, Melby K, et al. Gastric mucosal atrophy is a strong predictor of non-cardia gastric cancer but not of cardia cancer. Gastroenterology 1998;114:G2491.

10 Pera M Cardes A, Bombi JA, Ernst H, et al. Influence of esophagojejunostomy on the induction of adenocarcinoma of the distal esophagus in Sprague-Dawley rats by subcutaneous injection of 2,6-dimethylnitrosomorpholine. Cancer Res 1989;49:6803-8.

11 Xu X, LoCicero J III, Macri E, et al. Barrett's esophagus and assocaited adenocarcinoma in a mouse surgical model. J Surg Res 2000;88:120-4.

12 Leach S. Mechanisms of endogenous N-nitrosation. In: Hill J, ed. Nitrosoamines: Toxicology and Microbiology. Chichester: Ellis Holwood, 1988:69-87

13 Mirvish SS. Role of N-nitroso compounds (NOC) and N-nitrosation in etiology of gastric, esophageal, nasopharyngeal and bladder cancer and contributiion to cancer of known exposures to NOC. Cancer Lett 1995:93:17-48.

14 Gangolli SD, van den Brandt P, Feron VJ, et al. Nitrate, nitrite and $\mathrm{N}$-nitroso compounds. Eur J Pharmacol Environm Toxicol Pharmacol 1994;292: 1-38.
15 Van Maanen JM, van Geel AA, Kleinjans JC. Modulation of nitrate-nitrite conversion in the oral cavity. Cancer Detect Prev 1996:20:590-6.

16 Sasaki T, Matano K. formation of nitrite from nitrate at the dorsum linguae. J Food Hyg Soc 1979;20:363-9.

17 Boulos PB, Whitfield PF, Dover M, et al. Thiocyanate as a marker of saliva in gastric juice. Gut 1980;21:18-22.

18 Boyland E, Walker SA. Effect of thiocyanate on nitrosation of amines. Nature 1974;248:601-2.

19 Sobala GM Schorah CJ, Sanderson M et al. Ascorbic acid in the human stomach. Gastroenterology 1989;97:357-63.

20 Schorah CJ, Sobala GM, Sanderson M, et al. Gastric Juice Ascorbic Acid: Effects of Disease and Implications for Gastric Carcinogenesis. Am J Clin Nutr 1991;53:287-93S.

21 Mirvish SS. Inhibition by vitamins $C$ and $E$ of in vivo nitrosation and vitamin C occurrence in the stomach. Eur J Cancer Prev 1996;5:(suppl 1):131-6.

22 Mirvish SS. Blocking the formation of $\mathrm{N}$-nitrosocompounds with ascorbic acid in vitro and in vivo. Ann NY Acad Sci 1975;258:175-80.

23 Licht WR, Tannenbaum SR, Deen WM. Use of ascorbic acid to inhibit nitrosation: kinetic and mass transfer considerations for an in vitro system. Carcinogenesis 1988;9:365-72.

24 Archer MC, Tannenbaum SR, Fan T-Y, et al. Reaction of nitrite with ascorbate and its relation to nitrosamine formation. J Natl Cancer Inst 1975;54:1203-5.

25 Moriya A, Grant J, Williams C, et al. In vitro studies indicate that acid catalysed generation of $\mathrm{N}$-nitrosocompounds from dietary nitrate will be maximal at the gastroesophageal junction and cardia. Scand J Gastroenterol 2002;37:253-61.

26 lijima K, Henry E, Moriya A, et al. Dietary nitrate generates potentially mutagenic concentrations of nitric oxide at the gastroesophaeal junction. Gastroenterology 2002;1 22:1248-57.

27 Mowat C, Murray L, Hilditch TE, et al. Comparison of Helisal rapid blood test and ${ }^{14} \mathrm{C}$-urea breath test in determining Helicobacter pylori status and predicting ulcer disease in dyspeptic patients. Am J Gastroenterol 1998:93:20-5.

28 Muller M. Microdialysis. BM 2002;324:588-91

29 Suzuki H, lijima K, Moriya A, et al. Novel method for measuring nitrosation potential within localized regions of upper $\mathrm{Gl}$ tract. Gut 2002;51 (suppl II):A 110

30 Fletcher J, Wirz A, Young J, et al. Unbuffered highly acidic gastric juice exists at the gastresophageal junction after a meal. Gastroenterology 2001:121:775-83

31 Lundberg JON, Weitzberg E, Lundberg JM, et al. Intragastric nitric oxide production in humans: measurement in expelled air. Gut 1994;35:1543-6.

32 Sanderson MJ, Schorah CJ. Measurement of ascorbic acid and dehydroascorbic acid in gastric juice by high pressure liquid chromatography. Biomed Chromatogr 1987:2:197-202.

33 Varley H. Practical Clinical Biochemistry, 3rd edn. London: William Heinemann, 1963:636-7.

34 Mowat C, Carswell A, Wirz A, et al. Omeprazole and dietary nitrate independently affect levels of Vitamin C and nitrite in gastric juice. Gastroenterology 1999:116:813-22.

35 Dallinga JW, Pachen DMFA, Lousberg AHP, et al. Volatile $\mathrm{N}$-nitrosamines in gastric juice of patietns with various conditions of the gastrointestinal tract determined by gas chromatography-mass spectrometry and related to intragastric $\mathrm{pH}$ and nitrate and nitrite levels. Cancer Lett 1998; 124:1 19-25.

36 Bartholomew B, Hill M. The pharmacology of dietary nitrate and the origin of urinary nitrate. Food Chem Toxic 1984;22:789-93.

37 Hill MJ. N-nitroso compounds and human cancer. In: Hill M, ed. Nitrosoamines: Toxicology and Microbiology. Chichester: Ellis Holwood, 1988:142-61.

38 Hart RJ, Walters $\mathrm{CL}$. The formation of nitrite and $\mathrm{N}$-nitroso compounds in salivas in vitro and in vivo. Food Chem Toxic 1983;21:749-53.

39 Granli T, Dahl R, Brodin P, et al. Nitrate and nitrite concentrations in human saliva: variations with salivary flow-rate. Food Chem Toxic 1989:27:675-80

40 Liu X, Miller MS, Joshi MS, et al. Accelerated reaction of nitric oxide with $\mathrm{O}_{2}$ within the hydrophobic interior of biological membranes. Proc Natl Acad Sci U S A 1998;95:2175-9.

41 Waring AJ, Drake IM, Schorah CJ, et al. Ascorbic acid and total Vitamin C concentrations in plasma, gastric juice, and gastrointestinal mucosa: effects of gastritis and oral supplementation. Gut 1996;38: 171-6.

42 Haorah J, Miller DW, Brand R, et al. Diffusion of dialkylnitrosamines into the rat esophagus as a factor in esophageal carcinogenesis. Carcinogenesis 1999;20:825-36.

43 Smith TJ, Liao A, Wang L-D, et al. Characterization of xenobiotic-metabolizing enzymes and nitrosamine metabolism in the human esophagus. Carcinogenesis 1998:19:667-72.

44 Chen SC, Zhou L, Ding X, et al. Depentylation of the rat esophageal carcinogen, methyl-N-pentylnitrosamine, by microsomes from various human and rat tissues and by cytochrome P450 2A3. Drug Metab Dispos 2001;29:1221-8.

45 Xu GP, Reed PI. Instability of N-nitroso compounds in gastric juice and preliminary results from analyses of fresh samples by using an improved analytical method. Eur J Cancer Prev 1993:2:381-6.

46 Wink DA, Fellisch M, Vodovotz Y, et al. In: Gilbert DL, Coton CA, eds. Reactive Oxygen Species in Biological Systems. New York: Kluwer Academic/Plenum Publishers, 1999:245-91. 